Yu-Hua Liu • Yoshiro Koda • Mikiko Soejima $\cdot$ Hao Pang

Bao-Jie Wang • Doo-Sung Kim $\cdot$ Heung-Bum Oh

Hiroshi Kimura

\title{
The Fusion Gene at the ABO-Secretor Locus (FUT2): absence in Chinese populations
}

\begin{abstract}
The fusion gene $\left(s e^{f u s}\right)$ is a null allele of the secretor type $\alpha(1,2)$ fucosyltransferase gene $(F U T 2)$ and was first found in a Japanese population. It has not yet been reported in any other ethnic population. In the present study, we investigated the distribution of the fusion gene of the FUT2 locus in five populations from three ethnic groups in East Asia. The fusion gene was found in two additional Japanese populations with a high frequency (0.0551 in Okinawa and 0.0792 in Akita) and, for the first time outside Japan, in a Korean population, at a very low frequency (0.0063 in Seoul). In contrast, we found no fusion gene in two Chinese populations. These findings showed that the FUT2 fusion gene was ubiquitous in Japanese, but was rare in neighboring populations, suggesting that the FUT2 fusion gene had emerged from within the Japanese. Additionally, a new null allele with a C-to-T substitution at nucleotide 658 was found in one individual native of southern China.
\end{abstract}

Key words $\mathrm{ABO} \cdot$ Secretor $\cdot$ FUT2 $\cdot$ Fusion gene $\cdot$ Japanese

\section{Introduction}

The expression of $\mathrm{ABO}$ antigens in secretions such as saliva is regulated by the secretor gene (FUT2)-encoded $\alpha(1,2)$ fucosyltransferase (Se enzyme). The ABO secretor group

Yu-Hua Liu $\cdot$ Y. Koda $\cdot$ M. Soejima $\cdot$ H. Pang $\cdot$ H. Kimura $(\square)$ Division of Human Genetics, Department of Forensic Medicine, Kurume University School of Medicine, Kurume 830-0011, Japan Tel. +81-942-31-7554; Fax +81-942-31-7700

e-mail: hkimura@med.kurume-u.ac.jp

Y.-H. Liu $\cdot$ H. Pang $\cdot$ B.-J. Wang

Division of Serology, Faculty of Forensic Medicine, China Medical University, Shenyang, China

D.-S. Kim · Heung-Bum Oh

Division of Infectious Diseases, Research Institute for Blood

Transfusion, Korean Red Cross Central Blood Center, Seoul, Korea system has secretor and nonsecretor phenotypes. Secretors, who have $\mathrm{ABO}$ antigens in saliva, have at least one functional $\mathrm{Se}$ allele, and nonsecretors, who fail to express $\mathrm{ABO}$ antigens in saliva, are homozygous for the nonfunctional se allele. After the isolation of cDNA and genomic DNA of the FUT2 gene (Kelly et al. 1995; Koda et al. 1997a), molecular analysis of FUT2 has indicated that null alleles with a single base substitution in the protein coding region of FUT2 (G428A, A385T, C571T, C628T and G849A) were responsible for the inactivation of Se enzyme (Kelly et al. 1995; Yu et al. 1996; Koda et al. 1996). The findings from these studies suggested that these null alleles were geographic-specific and perhaps therefore race-specific. The null allele with the G428A mutation $\left(s e^{428}\right)$ was found to be common in Caucasians, while the null allele with the A385T $\left(s e^{357,385}\right)$ was found only in Asian populations (a nucleotide change at position 357 ( $\mathrm{C}$ to $\mathrm{T}$ ) is a synonymous mutation) (Kelly et al. 1995; Koda et al. 1996). The presence of racespecific null alleles of FUT2 is of interest because the frequency of the non-secretor phenotype is $20 \%-30 \%$, and the total frequency of nonfunctional alleles $(\mathrm{se})$ is $0.4-0.5$ in all ethnic groups so far examined (Liu et al. 1998). In addition to the point mutations mentioned above, we have reported two unusual alleles of FUT2; one was the fusion gene $\left(s e^{f u s}\right)$, consisting of the $5^{\prime}$-region of a pseudogene of $\alpha(1,2)$ fucosyltransferase and the $3^{\prime}$-region of the functional FUT2, and believed to be generated by unequal crossover, as one of inactive alleles of FUT2 in Japanese individuals (Koda et al. 1996), and the other was a complete deletion of the protein coding region of FUT2 $\left(s e^{\mathrm{del}}\right)$ in Indian individuals with the classical Bombay phenotype (Koda et al. 1997b). We have demonstrated the gene frequency of the sefus in Fukuoka, a southwestern region of Japan close to Korea, to be 0.0567 (Koda et al. 1996). However, the fusion gene of the FUT2 locus has never been found in any other ethnic group.

In this study, we investigated two Chinese populations, two additional Japanese populations, and a Korean population, to better understand the incidence of the $s e^{f u s}$ allele in populations of East Asia, since a considerably high frequency of the $s e^{f u s}$ has been found in Japanese populations (Koda et al. 1996; Narimatsu et al. 1998). 
Fig. 1. Gene frequencies of the fusion gene, FUT2, in various East Asian populations. Numbers in parentheses indicate numbers of the fusion gene/numbers of chromosomes tested. Data from Fukuoka and Tokyo are from Koda et al. (1996) and Narimatsu et al. (1998), respectively

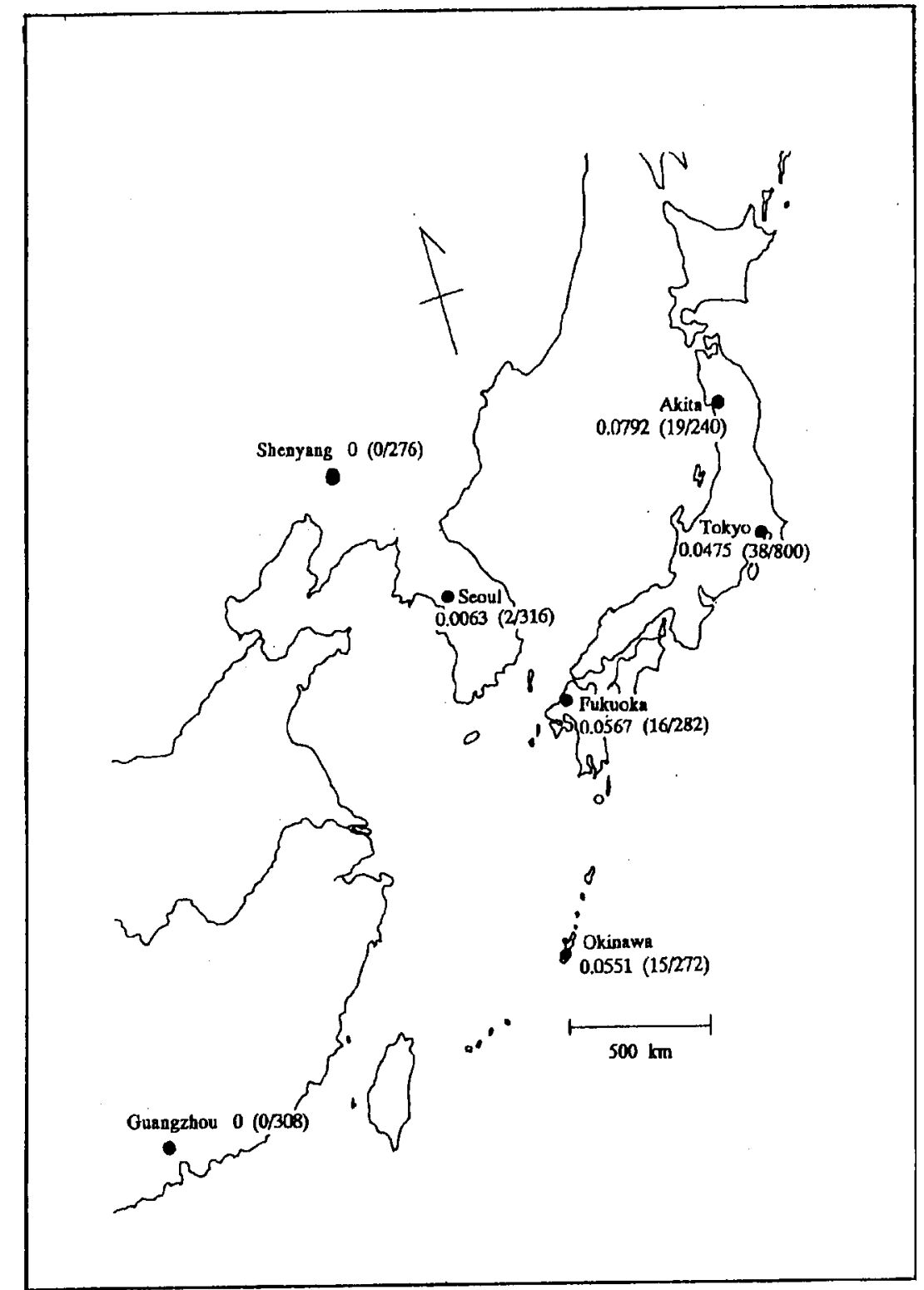

\section{Subjects and methods}

Samples and Lewis phenotypes

Blood samples were collected from random donors in five populations drawn from three ethnic groups in East Asia, and included 138 Shenyang Chinese (from the northern region of China), 154 Guangzhou Chinese (from the southern region of China), 158 Seoul Koreans, 120 Akita Japanese (from the northern region of the Japanese mainland), and 136 Okinawa Japanese (from the southernmost island of the Japanese archipelago). The Lewis phenotype on red blood cells was determined by a hemagglutination method using mouse monoclonal anti-Lea and anti-Leb antibodies
(Kokusai Reagents, Kobe, Japan). Genomic DNAs were prepared from leukocytes by a proteinase K-sodium dodecylsulfate (SDS) method (Liu et al. 1999).

Screening mutations of FUT2 by sequence-specific polymerase chain reaction (SSP-PCR) and PCR-restriction fragment length polymorphism (RFLP)

To detect the A385T and C571T mutations, sequence-specific PCR (SSP-PCR) was performed as described previously (Koda et al. 1996). The C357T and C628T substitutions were analyzed as described previously (Liu et al. 1998). To detect the G428A mutation, PCR products amplified by primers described by Kelly et al. (1995) were 
Table 1 Comparison of the Allelic Frequencies of FUT2 in East Asian populations

\begin{tabular}{|c|c|c|c|c|}
\hline \multirow{2}{*}{ Alleles $^{\text {a) }}$} & \multicolumn{2}{|c|}{ Chinese } & \multirow{2}{*}{$\begin{array}{l}\text { Korean } \\
\text { Seoul } \\
(n=158)\end{array}$} & \multirow{2}{*}{$\begin{array}{l}\text { Japanese } \\
\text { Fukuoka }^{\text {b) }} \\
(n=141)\end{array}$} \\
\hline & $\begin{array}{l}\text { Guangzhou } \\
(n=154)\end{array}$ & $\begin{array}{l}\text { Shenyang } \\
(n=138)\end{array}$ & & \\
\hline $\mathrm{Se}$ (wild type) & 0.1398 & 0.1595 & 0.1013 & 0.1028 \\
\hline$S e^{357}$ & 0.3506 & 0.3913 & 0.4051 & 0.4007 \\
\hline$s e_{357571}^{357,385}$ & 0.4805 & 0.4312 & 0.4873 & 0.4362 \\
\hline$s e^{357,571}$ & 0.0097 & 0.0072 & 0 & 0 \\
\hline$s e^{628}$ & 0 & 0 & 0 & 0.0036 \\
\hline$s e_{849}^{f u s}$ & 0 & 0 & 0.0063 & 0.0567 \\
\hline$s e_{429}^{\delta 49}$ & 0.0162 & 0.0036 & 0 & 0 \\
\hline$s e_{658}^{428}$ & 0 & 0.0072 & 0 & 0 \\
\hline$s e^{658}$ & 0.0032 & 0 & 0 & 0 \\
\hline
\end{tabular}

a) $\mathrm{Se}$ and se indicate a functional allele and a nonfunctional allele, respectively

${ }^{b)}$ Data from Koda et al. (1996)

cleaved by $M v a \mathrm{I}$ and then analyzed using $8 \%$ polyacrylamide gel electrophoresis. The fusion gene was detected using SSP-PCR, Southern blot hybridization, and DNA sequencing methods as described previously (Koda et al. 1996). Since the G849A substitution created a new endonuclease DdeI site (Yu et al. 1996), PCR products amplified by primers 571C (nt 545-571) and $3^{\prime}$-common (nt 1030-1056) (Koda et al. 1996) were digested by DdeI and then analyzed using $2 \%$ agarose gel electrophoresis. During screening of the G849A mutation, we incidentally found different sizes of DdeI-fragments (113 bp and 399 bp) in an individual from a Guangzhou population, compared with sizes of the DdeI-fragments in the G849A mutation (302 bp and $210 \mathrm{bp}$ ). The direct DNA sequencing of the PCR product from this individual demonstrated a single base substitution C-to-T at nucleotide 658 in the coding region of the $F U T 2$, which created a new endonuclease DdeI site (CTNAG).

\section{Nucleotide sequencing}

The fusion gene was amplified as described previously (Koda et al. 1996). The resulting PCR products were purified using Suprec-02 centrifugation tubes (Takara, Shiga, Japan), and then used for direct DNA sequencing with primers Se-seqU (5'-CCT GGC AGA ACT ACC ACC TG-39, nt 335-354) and Se-seqL (59-AGG GCC TGC TGT AGG TAT CG-3', nt 626-645) as described previously (Liu et al. 1998). Fifteen fusion genes and the FUT2 of one individual with the C658T mutation were used for direct DNA sequencing.

\section{Results and discussion}

We investigated the distribution of the fusion gene in 120 individuals in Akita and in 136 individuals in Okinawa, and found that the frequencies of the fusion gene were
0.0792 in Akita and 0.0551 in Okinawa (Fig. 1). However, surprisingly, we found no fusion gene in either of the two Chinese populations (138 individuals in Shenyang and 154 individuals in Guangzhou). We also investigated FUT2 in a Korean population (158 individuals in Seoul) and found two individuals having the $s e^{\text {fus }}$ in heterozygosity (frequency, 0.0063). The frequencies of other alleles of FUT2 in the Chinese and Korean populations are given in Table 1. The heterozygosity rate for the Shenyang Chinese, Guangzhou Chinese, Korean, and Fukuoka Japanese populations was calculated to be $0.6286 \pm 0.0152,0.6378 \pm$ $0.0128,0.5882 \pm 0.0131$, and $0.6376 \pm 0.0149$, respectively. The $s e^{357,385}$ was a common Se enzyme-deficient allele in the East Asian populations examined, and the $s e^{428}$, which is a common null allele in Africans and Caucasians (Liu et al. 1998), was quite rare in Asians (Table 1). Also, we found no fusion gene in 100 Caucasians and in 101 Africans (Xhosa) of South Africa (Liu et al. 1998). Accordingly, the fusion gene at the FUT2 locus appeared to be ubiquitous in Japanese. To examine whether any other nucleotide substitution (s) were present in this unusual recombinant allele, we sequenced about $1 \mathrm{~kb}$ of 15 fusion genes from individuals in Fukuoka, Akita, Okinawa, and Korea, and found no accumulation of any other nucleotide substitution in the sequences of the 15 fusion genes, suggesting that the fusion gene had emerged considerably recently.

During this study, we found a new nonsense mutation (C658T), which resulted in a change in the codon for Arg220 to a stop codon that consequently truncated a large portion (112 amino acid residues) of the catalytic domain of the C-terminal of the enzyme. The frequency of an allele containing the C658T substitution was investigated in both Chinese populations and a Korean population, and we found only one individual having this mutation in heterozygosity in a Guangzhou population.

The fusion gene of the FUT2 locus was found only in the Japanese and Korean populations and not in the two Chinese populations. The frequency of the fusion gene in the Japanese populations was $0.0475-0.0792$, whereas in the Korean population it was 0.0063 (Table 1; Narimatsu et al. 1998). Other alleles of polymorphic DNAs found in Japanese and Koreans and not in Chinese were the Y2 allele of the DXYS5Y locus (Nakagome et al. 1992) and the $A P R T^{*} J$ allele of the adenine phosphoribosyltransferase gene (Kamatani et al. 1996), while the $\mathrm{YAP}^{+}$allele of the DYS287 locus was present in the Japanese but not in the Koreans and not in the Chinese (Hammer and Horai 1995). However, the frequency of the $\mathrm{YAP}^{+}$has been reported to be highest in sub-Saharan African populations, followed by North African and then European populations. Most Asian populations examined so far, except Japanese ( $42 \%$ frequency) and Tibetan (50\% frequency) populations, have completely lacked the $\mathrm{YAP}^{+}$, demonstrating an irregular distribution of this polymorphism in Asia (Hammer and Horai 1995; Hammer et al. 1997). The ten fold higher frequency of the fusion gene in Japanese populations compared with a Korean population, and the findingof no fusion gene in Chinese popula- 
tions, suggested that the FUT2 fusion gene had emerged after the divergence of the Japanese-Korean group from other ethnic groups, and that the fusion gene had recently formed originally in the Japanese population and then very recently entered the Korean population. Further studies to determine the frequency of the FUT2 fusion gene in other ethnic groups, especially in other Asian populations, are required, since the fusion gene could show an irregular distribution in Asia in a fashion similar to that of the $\mathrm{YAP}^{+}$allele.

While there are many somewhat conflicting theories concerning the origin of the modern Japanese, Hanihara (1991) has proposed a dual structure theory of Japanese origins, based on the anthropometric characteristics of fossils, in which modern Japanese are the result of an intermixture between the upper Paleolithic native population of Japan and migrants from northeast Asia via the Korean peninsula during the Aeneolithic Yayoi period (300 BC300 AD). An analysis of 25 classic genetic markers by Omoto and Saitou (1997) supported this dual structure theory. The analysis of the nucleotide sequences of the Dloop region of mitochondrial DNA from five East Asian populations by Horai et al. (1996) also supported this dual structure theory, and suggested that a great majority of the gene pool of the mainland Japanese was derived from the Asian continent during the Yayoi period. However, Nei (1995) argued against the dual structure theory by analyzing 18 protein polymorphic loci. He suggested that Japanese groups were derived from Northeast Asians and were formed 12000 - 30000 years ago, and that the contribution from migrants via the Korean peninsula to the Japanese gene pool was relatively insignificant (transformation theory). After the Japanese archipelago was formed by disconnection from the Asian continent about 12000 years ago, the gene pool of populations in Japan was transformed independently of continental Asian groups to form the modern Japanese of the Japanese archipelago, consequently resulting in the ubiquitous presence of the $\mathrm{YAP}^{+}$ allele of the DYS287, the Y2 allele of the DXYS5Y, the $A P R T^{*} J$ allele, and the FUT2 fusion gene in the Japan mainland.

Acknowledgments We are greatly indebted to the Red Cross Blood Centers in Akita and in Okinawa for their kind gift of blood samples. We thank Mr. Shigeo Kamimura and Miss Yasuko Noguchi for their technical assistance. This work was supported in part by Grants-in-Aid for General Scientific Research and International Scientific Research from the Ministry of Education, Science, Culture, and Sports of Japan.

\section{References}

Hammer MF, Horai S (1995) Y chromosomal DNA variation and the peopling of Japan. Am J Hum Genet 56: 951-962

Hammer MF, Spurdle AB, Karafet T, Bonner MR, Wood ET, Novelletto A, Malaspina P, Mitchell RJ, Horai S, Jenkins T, Zegura SL (1997) The geographic distribution of human Y chromosome variation. Genetics 145: 787-806

Hanihara K (1991) Dual structure model for the population history of the Japanese. Japan Review 2: 1-33

Horai S, Murayama K, Hayasaka K, Matsubayashi S, Hattori Y, Fucharoen G, Harihara S, Park K-S, Omoto K, Pan I-H (1996) mtDNA polymorphism in East Asian populations, with special reference to the peopling of Japan. Am J Hum Genet 59: 579-590

Kamatani N, Terai C, Kim S-Y, Chen C-L, Yamanaka H, Hakoda M, Totokawa S, Kashiwazaki S (1996) The origin of the most common mutation of adenine phosphoribosyltransferase among Japanese goes back to a prehistoric era. Hum Genet 98: 596-699

Kelly RJ, Rouquier S, Giorgi D, Lennon GG, Lowe JB (1995) Sequence and expression of a candidate for the human secretor blood group $\alpha(1,2)$-fucosyltransferase gene (FUT2): homozygosity for an enzyme-inactivating nonsense mutation commonly correlates with the non-secretor phenotype. J Biol Chem 270:4640-4649

Koda Y, Soejima M, Liu Y-H, Kimura H (1996) Molecular basis for secretor type $\alpha(1,2)$-fucosyltransferase gene deficiency in a Japanese population: a fusion gene generated by unequal crossover responsible for the enzyme deficiency. Am J Hum Genet 59: 343-350

Koda Y, Soejima M, Kimura H (1997a) Structure and expression of the gene encoding secretor-type galactoside 2- $\alpha$-L-fucosyltransferase (FUT2). Eur J Biochem 246: 750-755

Koda Y, Soejima M, Johnson PH, Smart E, Kimura H (1997b) Missense mutation of FUT1 and deletion of FUT2 are responsible for Indian Bombay phenotype of ABO blood group system. Biochem Biophys Res Commum 238: 21-25

Liu Y-H, Koda Y, Soejima M, Pang H, Schlaphoff T, du Toit ED, Kimura H (1998) Extensive polymorphism of the FUT2 gene in an African (Xhosa) population of South Africa. Hum Genet 103: 204-210

Liu Y-H, Koda Y, Soejima M, Pang H, Wang B-J, Kimura H (1999) Lewis (FUT3) genotypes in two different Chinese populations. J Forensic Sci 44: 82-86

Nakagome Y, Young S-R, Akane A, Numabe H, Jin D-K, Yamori Y, Seki S, Tamura T, Nagafuchi S, Shiono H, Nakahori Y (1992) A Yassociated allele may be characteristic of certain ethnic groups in Asia. Ann Hum Genet 56: 311-314

Narimatsu H, Iwasaki H, Nakayama F, Ikehara Y, Kudo T, Nishihara S, Sugano K, Okuda H, Fujita S, Hirohashi S (1998) Lewis and Secretor gene dosages affect CA19-9 and DU-PAN-2 serum levels in normal individuals and colorectal cancer patients. Cancer Res 58: 512-518

Nei M (1995) The origin of human populations: genetic, linguistic and archeological data. In: Brenner S, Hanihara K (eds) The origin and past of modern humans as viewed from DNA. World Scientific, Singapore, pp 71-91

Omoto K, Saitou N (1997) Genetic origin of the Japanese: a partial support for the dual structure hypothesis. Am J Phys Anthropol 102: 437-446

Yu L-C, Broadberry RE, Yang Y-H, Chen Y-H, Lin M (1996) Heterogeneity of the human secretor $\alpha(1,2)$ fucosyltransferase gene among Lewis (a+b-) non-secretors. Biochem Biophys Res Commun 222: 390-394 